
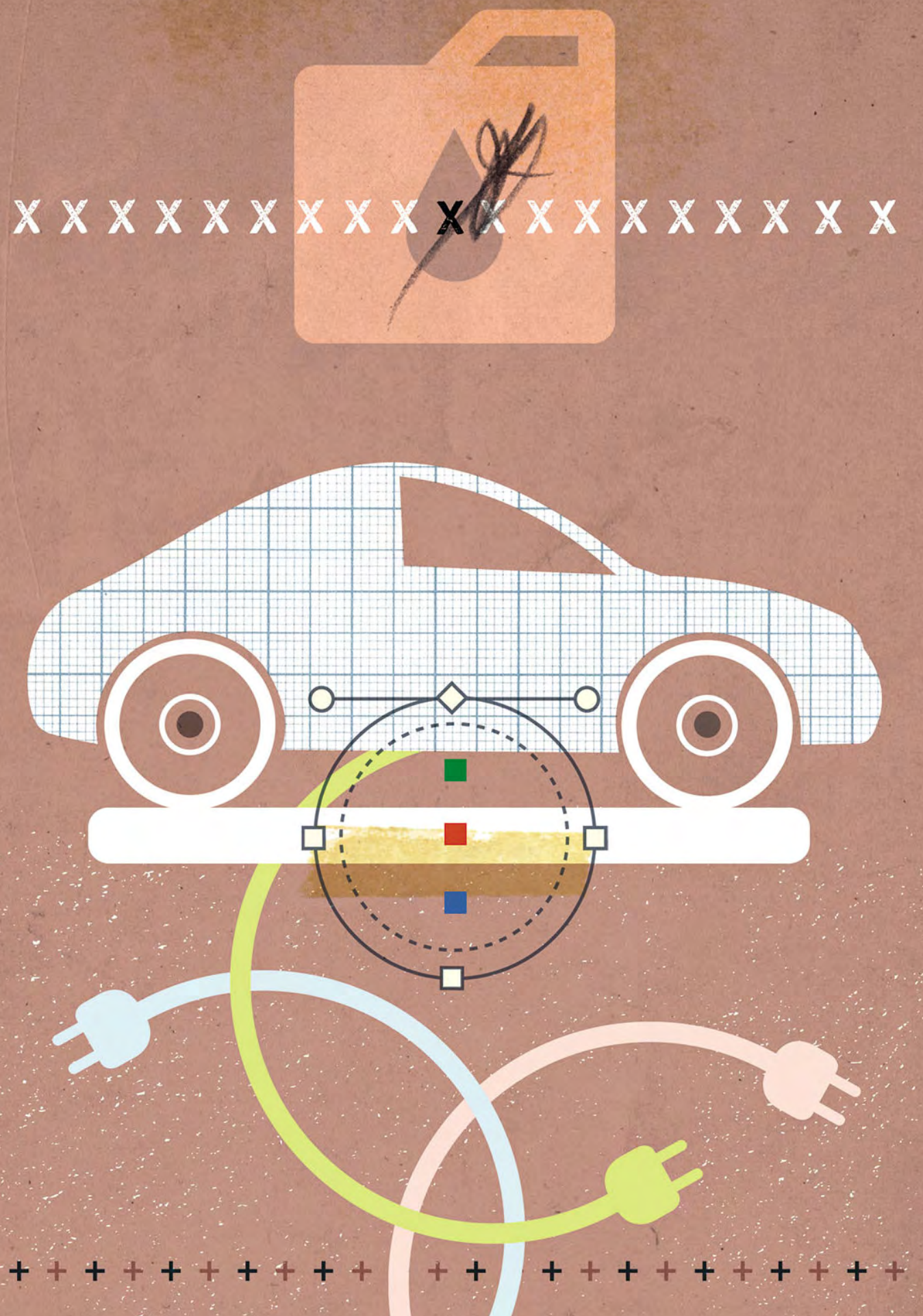


\title{
Infraestrutura de recarga de bateria e subsídios e incentivos fiscais: condições chave para a difusão do corro elétrico
}

\author{
Battery recharging infrastructure and \\ subsidies and tox incentives:key conditions \\ for the spread of electric car
}

${ }^{*}$ Claudia do Nascimento Martins

\section{Resumo}

No início da indústria automobilística os carros movidos a vapor, a eletricidade e a combustão interna eram opções de uso e concorriam entre si, mas o surgimento de uma infraestrutura de abastecimento própria para os carros a gasolina, tornaram esses carros dominantes. Com as questões ambientais em evidência, os desafios para difundir o carro puramente elétrico ultrapassam questões técnicas, considerando que inovações e desenvolvimento vêm ocorrendo. A necessidade de infraestrutura de recarga da bateria, como também de incentivos fiscais e subsídios para torná-lo atraente ao consumidor são analisados neste artigo, que é parte da tese doutoral produzida no PPED-IE-UFRJ'.

Palavras-chave: carro elétrico, ativos complementares, infraestrutura de recarga da bateria, subsídios e incentivos fiscais.

\begin{abstract}
At the beginning of the automobile industry, cars powered by steam, electricity and internal combustion were options of usage and competed with each other, but the emergence of a supply infrastructure for gasoline cars, made these cars dominant. With environmental issues in evidence, the challenges to spread the purely electric car went beyond technical issues, considering that innovations and development have been taking place. The need of battery recharging infrastructure, as well as tax incentives and subsidies to make it attractive to the consumer are analyzed in this article, which is part of the doctoral thesis produced on PPED-IE-UFRJ.
\end{abstract}

Keywords: electric car, complementary assets, battery recharging infrastructure, subsidies and tax incentives.

\footnotetext{
* Doutora em Ciências, em Políticas Públicas, Estratégias e Desenvolvimento (PPED-IE-UFRJ). Mestre em Economia (UFF). Economista. Professora da Universidade Veiga de Almeida (RJ). 


\section{Introdução}

As discussões em relação ao surgimento e ampla utilização de carros elétricos cujas baterias possam ser carregadas a partir da rede local vêm ganhando destaque no cenário internacional. De um lado apresenta-se um novo mercado que diversos agentes buscam explorar e, de outro, encontram-se governos com a missão de reduzir tanto a dependência de combustíveis fósseis quanto à poluição urbana e à emissão de gases de efeito estufa. Na realidade o carro puramente elétrico - alimentado apenas por baterias recarregáveis - não é uma tecnologia nova, cuja origem data de meados do século XIX quando os primeiros modelos foram projetados e construídos.

A indústria automobilística se desenvolveu rapidamente na década de $1890 \mathrm{com}$ seu mercado sendo dividido principalmente entre elétrico e vapor. Em 1899, foram vendidos nos Estados Unidos 1575 carros elétricos, 1681 carros a vapor e 936 carros a gasolina. Entretanto, no período de 1899-1909, enquanto as vendas de carros elétricos naquele país mais do que duplicaram, as vendas de carros a gasolina aumentaram mais de 120 vezes. Nos primeiros anos do século XX o carro a gasolina superou seus concorrentes no mercado americano, enquanto que a mesma evolução já se apresentava na França, Grã-Bretanha e na Alemanha em anos anteriores. (COWAN e HÚLTEN, 1996)

Na realidade não foram as vantagens técnicas que levaram o motor a combustão interna ao patamar de tecnologia dominante e, futuramente, única na propulsão veicular. $O$ argumento é que se, na virada do século XIX para o século XX, a indústria automobilística tivesse decidido utilizar energia elétrica, a pesquisa nesse ramo teria avançado o suficiente para tornar essa tecnologia tão eficiente, se não mais, do que a atualmente utilizada. Assim, segundo Freeman e Soete (2008, p. 244)

as redes de estações de reabastecimento, das oficinas de reparo e de manutenção, poderiam ter sido concebivelmente organizadas de forma diferente, diante de diversas estratégias e políticas das empresas de utilidade pública, dos fabricantes e dos órgãos reguladores.

A questão da deficiência na infraestrutura de abastecimento para os carros elétricos tornou-se um grande problema para os usuários nos Estados Unidos. As áreas urbanas do país começaram a usar mais energia elétrica principalmente com a introdução de lâmpadas e apenas as pessoas com maior poder aquisitivo tinham energia elétrica instalada nas suas casas. Nas áreas rurais, a eletricidade era praticamente inexistente, 0 que manteve os motoristas de carros elétricos perto de suas residências, considerando a baixa autonomia desses carros. A utilidade dos carros elétricos se restringiu às áreas urbanas enquanto à locomoção entre cidades ficou a cargo dos carros movidos a gasolina.

De acordo com Mowery e Rosenberg (2005) as vantagens, nos Estados Unidos, do motor a combustão interna em relação às duas outras formas de propulsão vapor e eletricidade - ocorreram devido a superior infraestrutura criada para o seu 
abastecimento como também o baixo custo local da gasolina, em relação ao da energia elétrica, proporcionando menor custo operacional. De acordo com Flink (apud MOWERY e ROSENBERG, 2005, p. 63) “o custo de dirigir um carro elétrico de Boston a Nova York em 1903 era quatro vezes maior do que o custo de dirigir um carro movido a gasolina na mesma rota".

Apesar das qualidades dos carros elétricos, a formação da indústria do petróleo, que passou a gerar lucros extraordinários foi, passo a passo, freando as pesquisas que possivelmente aconteceriam para solucionar as deficiências dos carros elétricos, já que um setor automotivo começou a prosperar com base no motor a gasolina. As limitações do tempo de recarga e autonomia dos elétricos não resistiram ao sucesso iniciado com o lançamento do Modelo T, carro da Ford a gasolina em 1908, e com seus aperfeiçoamentos como a partida elétrica. Essa inovação desempenhou importante papel na ascensão de um dos produtos mais almejados e disputados pela sociedade de consumo: o automóvel. Para Freeman e Soete (2008) a principal razão para o grande aprisionamento (lock-in) aos motores de combustão interna foi devido, de forma natural, ao sucesso das linhas de montagem de Ford que reduziram drasticamente os custos e os preços do Modelo T. De acordo com Freeman e Soete (2008, p. 245)

\begin{abstract}
o preço dos carros elétricos estavam subindo naquela época devido à introdução de melhores baterias, mas os dos Modelo T caíram de US\$850 em 1908 para US\$ 600 em 1913 e para US\$ 360 em 1916, devido a uma combinação de inovações organizacionais, técnicas e sociais. De forma pouco surpreendente, as vendas do Modelo T multiplicaram-se por cinquenta e a participação de mercado deles aumentou de 10\% em 1909 para 60\% em 1921. Os lucros sobre o valor líquido chegaram por vezes a atingir o nível de $300 \%$ ao ano, e os EUA alcançaram uma posição dominante no mercado mundial desses veículos.
\end{abstract}

Noinício do séculoXXobserva-sea perda de competitividadee,consequentemente, de motivação para os investimentos em carros elétricos. Desta forma, a crescente disponibilidade de postos de abastecimento associado à redução contínua dos preços da gasolina e maior disponibilidade dos derivados de petróleo favoreceu a conquista do mercado pelos carros com motor a combustão interna.

$O$ desenvolvimento de ativos complementares no início do século $X X$, especialmente refinarias, distribuidoras e postos de abastecimento, resultaram no surgimento de grandes corporações de petróleo que acabaram por empurrar o uso da gasolina. De acordo com Teece (1986), inovações tecnológicas requerem o uso de determinados ativos para produzir e distribuir novos produtos e serviços, ou seja, requer o uso de um conjunto de outras capacidades ou ativos que são complementares.

Na maior parte do século XX, crescer dependendo do petróleo era universalmente considerado um fato real. Entretanto no século XXI a dinâmica da civilização do petróleo começa a ser contestada tanto pelo argumento do esgotamento em um futuro breve das jazidas de petróleo, quanto pelo crescimento do movimento ecológico. Desta forma, os princípios da sociedade industrial estão sendo desafiados, colocando 
em xeque o modelo - baseado no petróleo - no qual a civilização foi construída e sustentada ao longo do século XX.

O desenvolvimento cumulativo de tecnologias e a crescente quantidade de veículos movidos a combustão, que emitem gases poluentes, têm sido apontados como fatores que prejudicam o meio ambiente favorecendo o aquecimento global, cujos efeitos, danosos ao desenvolvimento, reacenderem a ideia do carro elétrico devido à busca por tecnologias limpas. Nesse contexto o artigo tem como objetivo evidenciar os movimentos que estão sendo realizados em favor da criação de infraestrutura de recarga de bateria, como também as ações de diferentes países, no que se refere aos subsídios e incentivos fiscais, com o intuito de equipar o preço dos carros elétricos aos carros convencionais. Políticas estas, dirigidas à difusão do carro elétrico, são fundamentais para tornar o carro elétrico não apenas atraente ao consumidor como também tornar possível a conversão de nossa mobilidade arraigada na explosão de combustíveis fósseis para tração elétrica.

\section{Infraestrutura de recarga da bateria}

Uma das grandes restrições ao consumo do carro elétrico, além do seu alto preço e a relativa baixa autonomia, é a recarga da sua bateria. A precariedade de infraestrutura de recarga age como um empecilho à aquisição do veículo. A infraestrutura de abastecimento inclui equipamentos de recarga, medidores de consumo e formas de cobrança, localizados em locais de estacionamento demorado e em vias públicas. Na realidade as estações de recarga podem se situar, no geral, da seguinte forma:

- doméstico: que inclui garagens de casas e apartamentos residenciais podendo ser usado para abastecer carros elétricos durante toda a noite;

- local de trabalho: que inclui garagens de escritório onde os carros elétricos podem ser abastecidos em 7-8 horas;

- $\quad$ público: que inclui vias públicas e em locais de estacionamento demorado como supermercados e shoppings onde a recarga de baterias pode ser feita em cerca de 3-4 horas (se a recarga for rápida) ou 20-30 minutos (se a recarga for muito rápida - quick charge);

- $\quad$ troca de bateria (swap) - modelo quick drop: estações de bateria semelhantes em conceito de postos de gasolina onde a troca de baterias é realizada em 2-3 minutos. (INSTITUTION OF MECHANICAL ENGINEERS, 2010)

A grande desvantagem dos carros totalmente elétricos é o tempo necessário para recarregar suas baterias. Com a tecnologia da bateria de íon de lítio, um carro elétrico completamente recarregado consegue alcançar uma distância comparável a de um motor de combustão interna com o tanque de combustível completo, porém precisará ser conectado a um recarregador no fim desse tempo. Atualmente isso significa que 
um carro elétrico com bateria descarregada estará fora de operação durante várias horas antes de estar totalmente recarregado, tornando-se uma grande desvantagem.

No futuro, com o desenvolvimento tecnológico, tecnologias de recarga mais rápidas poderão ser disponibilizadas superando a deficiência dos carros elétricos em viagens longas. As estações de troca de bateria swap seria uma possível solução para o problema de recarga, pois haveria uma simples troca de uma bateria descarregada por uma nova totalmente carregada, diminuindo sensivelmente o tempo necessário para ter o carro elétrico pronto para se locomover novamente. Porém o custo elevado de uma estação swap, comparado às estações de recarga rápida (quick charge) tornou a tecnologia inadequada. Logo, a questão da infraestrutura de abastecimento ainda é grande obstáculo à difusão do carro elétrico.

\section{Experiências internacionais}

Alguns países vêm apresentando movimentos em direção à criação de infraestrutura de recarga. Em 2009, o governo português anunciou a implementação do Programa para a Mobilidade Elétrica em Portugal, que tem como principais objetivos a criação tanto de uma rede de carregamento - o Mobi. E - como um modelo de serviço para o carro elétrico. O Programa, centrado no usuário, visa implantar uma rede de carregamento acessível em qualquer ponto de Portugal e compatível com todas as marcas do veículo e aberta a todos os operadores (ADENE, 2015). A rede de carregamento Mobi.E tem como metas fornecer bases para a difusão do veículo elétrico, nas suas mais variadas vertentes e tipologias; projetar o país como estudo de caso internacional, promovendo a liderança de Portugal em soluções de carregamento de carros elétricos; além de proporcionar, em parceria entre empresas e centros de excelência, condições para gerar e atrair investimentos para o desenvolvimento de soluções para a mobilidade elétrica (ADENE, 2015).

Na Holanda a Fastned firmou parceria com a ABB, o grupo líder em tecnologias de eletricidade e automação, para fornecer a maior rede de carregamento rápido do país. Serão cerca de 200 postos espalhados pelas estradas do país, com capacidade para reabastecer um veículo em 15 a 30 minutos. A construção dos pontos de abastecimento deve ser concluída até 2015. Os equipamentos de recarga serão fornecidos pela ABB e cada carregador terá uma série de recursos de conectividade, como assistência remota, gerenciamento, manutenção e atualizações inteligentes de software (AUTOMOTIVE BUSINESS (a), 2015).

O plano para instalar postos de carregamento rápido de carros elétricos nas autoestradas holandesas foi iniciado em 2011, quando a Fastned pediu autorização ao Ministério de Infraestrutura para instalar uma rede de carregamento de veículos elétricos. Em dezembro de 2011, o governo holandês anunciou o lançamento de um processo de licitação para fornecer instalações de carregamento para as 245 estações de serviço existentes nas suas autoestradas. A Fastned, que ganhou a concessão para 
201 estações, é uma empresa holandesa fundada em 2011 por Bart Lubbers e Michiel Langezaal com o objetivo de gerar uma infraestrutura de carregamento de âmbito nacional. A lógica do negócio baseia-se no conceito de que o primeiro a entrar nesse mercado poderá escolher as melhores localizações para o carregamento rápido no país, o que justifica um investimento precoce. Enquanto que a $A B B$, que opera em cerca de 100 países, sua parceira no projeto, é líder em tecnologias de energia e automação, possibilitando às empresas de eletricidade, água e gás, e à indústria, melhorar o seu desempenho, reduzindo o impacto ambiental. (ABB GROUP - AUTOMATION AND POWER TECHNOLOGIES, 2015).

A Europa usa o padrão Open Charge Point Protocol (OCPP) para que os veículos elétricos estejam aptos a usar quaisquer estações. Significa um protocolo de aplicação para a comunicação entre estações de carregamento de carros elétricos e um sistema de gerenciamento central, também conhecido como uma rede de estações de carregamento, semelhante aos telefones celulares e redes de telefonia celular. $\mathrm{O}$ Open Charge Point Protocol é uma iniciativa da fundação E-Laad na Holanda e tem como objetivo criar um protocolo de aplicativo aberto que permite que estações de carregamento de carros elétricos e sistemas de gestão centrais de diferentes fornecedores possam se comunicar uns com os outros (GREEN TRANSPORTATION. INFO, 2014).

A montadora japonesa Toyota assinou, em 2013, contrato com a WiTricity Corp. (Wireless Electricity Delivered Over Distance), empresa que licencia tecnologia de recarga wireless para carros elétricos e híbridos (caso 5), com o objetivo de lançar no futuro veículos capazes de reabastecer baterias sem o uso de cabos. (CROWN CROATION WORLD NETWORK, 2014). Além da WiTricity, outras empresas trabalham em sistemas de recarga wireless para carros elétricos, como a HEVO Power (Hybrid e Electric Vehicle Optimization). A tecnologia da Hevo Power para carregar um carro elétrico consiste em três componentes (Figura 1): (1) power station, é a superfície montada ou enterrada no chão e se conecta à energia fornecida pela rede; (2) wireless receiver, que é equipada em qualquer carro elétrico e se conecta ao sistema de gestão da bateria; e (3) mobile app, permite a comunicação entre os componentes de hardware, agindo como a única interface com o usuário final (HEVO POWER, 2014).

Nos Estados Unidos a empresa Better Place, fundada em 2007 na Califórnia, criou o modelo de quick drop baseado na troca de bateria (swap) em postos específicos em menos de quatro minutos, exigindo que o carro seja projetado para permitir essa operação. Os altos custos de troca de baterias, adicionado ao fato de restringir seu serviço a apenas um único modelo de carro elétrico - o Renault Fluence Z.E., levaram a Better Place a entrar em processo de falência em maio de 2013. Apesar dos problemas a ideia permanece, tanto que a Tesla Motors desenvolve um modelo de troca de baterias em São Francisco e Los Angeles, nos Estados Unidos (FAST COMPANY, 2014; TRANSPORT EVOLVED, 2014). A ideia parece excelente, mas a questão é que é uma tecnologia muito cara, pois tem que se estocar alguns packs de baterias; Além disso, 
o preço das estações é muito alto e o tempo que levaria a troca das baterias seria o mesmo em uma estação quick drop de recarga de bateria.

Figura 1 - Mecanismo de funcionamento da Hevo Power:

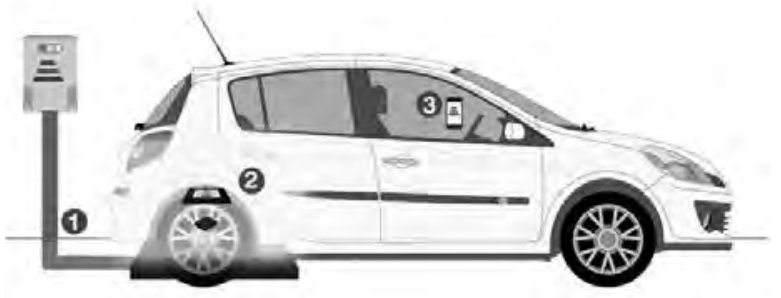

(1) power station,

(2) wireless receive, $\mathrm{e}$

Fonte: HEVO POWER, 2014.

(3) mobile app

A cidade de Palo Alto, na Califórnia, região que se consolida na vanguarda da tecnologia mundial sediando empresas como Google, Apple, Facebook e Tesla Motors, desenvolve um projeto para incluir tomadas especiais para carros elétricos em todas as casas novas. A norma foi aceita, por unanimidade, pelo conselho local e o argumento é que com apenas U\$ 200 pode-se realizar uma instalação de uma estação de carregamento suficiente para dois veículos. O custo de instalação em uma residência nova é de cerca de um quarto do custo de instalação da estação em uma casa já construída. O conselho de Palo Alto objetiva incentivar a aceitação dos carros elétricos estudando a instalação de estações energéticas de carregamento rápido como forma de incentivar a aceitação desses carros na região (THE VERGE, 2014).

No início de 2012 a Tesla Motors construiu estações chamados Superchargers nos Estados Unidos, Europa e Ásia, projetadas para carregar as baterias de forma rápida e sem custo adicional para os proprietários de um Tesla. Os Superchargers fornecem meia carga em menos de 20 minutos e são estrategicamente colocados próximos a restaurantes de estradas, cafés e centros comerciais, para permitir que os proprietários de carro possam dirigir de estação para estação, com paradas mínimas. Nos Estados Unidos são atualmente 131 estações de recarga de baterias, na Europa são 98 e na Ásia 36. (TESLA, 2014)

Na França a Renault implantou coberturas fotovoltaicas nas fábricas em Douai, Mauberge, Flins, Batilly, Sandouville e Cléon, nas quais seus pátios de veículos ou estacionamentos foram cobertos pelos painéis, totalizando 400 mil metros quadrados de área. As coberturas fotovoltaicas somadas são capazes de gerar $59 \mathrm{MW}$, equivalente a uma produção de $52.600 \mathrm{MWh}$ por ano, algo como o consumo anual de uma cidade de 15 mil habitantes. (AUTOMOTIVE BUSINESS (b), 2015)

\section{Iniciativas no Brasil}

A CPFL Energia (Companhia Paulista de Força e Luz) iniciou em 2013 o Projeto de Pesquisa \& Desenvolvimento “Projeto PD-0063-0060/2013 - PA0060 - MOBILIDADE 
ELÉTRICA - INSERÇÃO TÉCNICA E COMERCIAL DE VEÍCULOS ELÉTRICOS EM FROTAS EMPRESARIAIS DA REGIÃO METROPOLITANA DE CAMPINAS do Programa de Pesquisa e Desenvolvimento Tecnológico do Setor de Energia Elétrica das empresas CPFL Paulista, CPFL Piratininga e RGE, do Programa de $P \& D$ regulado pela ANEEL", integrando carros elétricos nas frotas de grandes empresas da região. O projeto visa construir um laboratório real de mobilidade elétrica na região metropolitana de Campinas, com o intuito de criar condições para a realização dos estudos de impacto da mobilidade elétrica no setor elétrico. (informações CPFL Energia , outubro de 2014)

Entre os objetivos do projeto da CPFLEnergia, destacam-se a avaliação dos impactos do carro elétrico na rede de distribuição de energia como possíveis interferências, demanda de energia necessária e adequações dos padrões construtivos. Além disso, estuda a proposição de regulamento tarifário para a cobrança das recargas como, por exemplo, horário de carregamento e cobrança em roaming ${ }^{2}$ além da realização de diversos outros estudos acadêmicos para a desmistificação do tema de mobilidade elétrica no país. O projeto busca o entendimento do modelo de negócio das distribuidoras de energia elétrica com os carros elétricos e desenvolve competências de provedor, instalador e explorador de infraestruturas de recarregamento. Até o momento participam desse projeto, como entidades executoras, o CPqD (Centro de Pesquisa e Desenvolvimento em Telecomunicações), a Universidade Estadual de Campinas e, como parceiros frotistas ${ }^{3}$ na construção desse laboratório real, as empresas Natura e 3M, que utilizam os carros em sua frota, permitindo a compreensão real da mobilidade elétrica. Em contrapartida, realizam o pagamento de uma quantia mensal pela utilização dos veículos, que são fornecidos pela Renault-Nissan, que fomentará as pesquisas. (informações CPFL Energia, outubro de 2014)

A Renault inaugurou em sua unidade de São José dos Pinhais, Paraná - o Complexo Airton Senna - um conjunto de painéis fotovoltaicos com 132 metros quadrados de área para a geração de energia a partir da captação da luz solar, que será direcionada ao abastecimento dos carros elétricos da marca, Zoe, Twizy e Kangoo, além de distribuí-la para a rede de iluminação próxima às instalações. $O$ conjunto é formado por 80 placas com capacidade de gerar $20 \mathrm{kwh}$ e captada de forma contínua durante o dia, inclusive em dias nublados e com baixa luminosidade. A geração é suficiente para recarregar as baterias de um carro elétrico em 2 horas. (AUTOMOTIVE BUSINESS (b), 2015)

Juntamente com a inauguração do sistema fotovoltaico da Renault, no Complexo Ayrton Senna, começou a operar também, um eletroposto com a possibilidade de carregamento de até dois carros elétricos simultaneamente. O sistema foi homologado pela Agência Nacional de Energia Elétrica (Aneel), reconhecido e aprovado pela Companhia Paranaense de Energia (Copel). (AUTOMOTIVE BUSINESS (b), 2015)

O recarregamento do carro elétrico no Brasil é realizado por meio dos eletropostos. No tipo wallbox (carregador residencial) é possível recarregar nas casas que demora de 6 a 8 horas para completar $100 \%$ da carga da bateria. Dependendo do fabricante este pode fornecer o serviço de eletroposto para a residência, caso contrário é necessário 
comprar o equipamento, contratando um profissional para realizar as adequações e instalação. Entretanto se a moradia for em um edifício não é possível instalar o wallbox, utilizando então a infraestrutura pública existente. Existe infraestrutura considerada semi rápida com recarregamento de 2 horas, e uma outra com recarga de $80 \%$ na primeira meia hora e $20 \%$ na meia hora restante, completando $100 \%$.

Atualmente os eletropostos públicos no Brasil oferecem recarga de bateria gratuitamente pois não existe regulamento e legislação que trate do tema, logo não é permitido cobrar a energia recarregada. Assim, a ausência de regulação para a recarga no Brasil indica a manutenção de uma infraestrutura de abastecimento que está restrita a programas pilotos em algumas cidades. Para apoiar a difusão do carro elétrico há a necessidade, portanto, de legislação que abra caminho para o desenvolvimento dos carros elétricos.

\section{Subsídios e incentivos fiscais ao carro elétrico}

Governos, motivados por metas de longo prazo para frear mudanças climáticas e o aquecimento global juntamente com a redução do uso do petróleo, vêm estabelecendo metas para aumentar a participação no mercado dos carros elétricos. Em apoio a esses objetivos alguns governos estão concedendo subsídios, incentivos fiscais e implementando políticas regulatórias para ajudar a acelerar o movimento de carros elétricos no mercado.

\section{Panorama internacional}

De acordo com Mock e Yang (2014) existem inúmeros incentivos públicos destinados a equipar o preço dos carros elétricos com os carros convencionais com o objetivo de aumentar suas vendas, dentre eles subsídios diretos, incentivos fiscais e economia no custo de combustível. Assim, tendo como base o relatório de Mock e Yang (2014), listam-se, em seguida, países que têm adotado esses incentivos:

\section{Subsídios diretos}

São oferecidos por uma série de países na compra de um carro elétrico, como:

- França: carros com emissões de $\mathrm{CO}_{2}$ inferiores a $20 \mathrm{~g} / \mathrm{km}$ recebem um bônus único de 7.000 euros e, para carros entre 21 e $50 \mathrm{~g} / \mathrm{km}$ de emissão de $\mathrm{CO}_{2^{\prime}}$ como o Volvo V60 plug-in, o bônus é de 5.000 euros. O valor do incentivo não pode exceder $30 \%$ do preço de compra do veículo, incluindo o VAT (valueadded tax) ${ }^{4}$ e o custo da bateria.

- $\quad$ Reino Unido: desde 2011, os consumidores que compram um carro elétrico novo (totalmente elétrico ou híbrido plug-in) que emite menos de $75 \mathrm{~g}$ de $\mathrm{CO}_{2} / \mathrm{km}$ recebem um bônus de $25 \%$ do valor do carro, até a um máximo de 5.000 libras (cerca de 5.800 euros). 
- Suécia: programa executado de 2012 a 2014, em que um máximo de 5.000 carros com emissões de $\mathrm{CO}_{2}$ de $50 \mathrm{~g} / \mathrm{km}$ ou menos, receberam, uma única vez, 40.000 coroas suecas (cerca de 4.500 euros).

- $\quad$ EUA : um programa de subsídio federal permite um bônus único, dependendo da capacidade da bateria do carro, de até um máximo de 7.500 dólares em forma de crédito fiscal. Para o Renault Zoe (totalmente elétrico), o bônus seria de 7.500 dólares enquanto que para o Volvo híbrido plug-in V60 seria de 5.400 dólares. Na Califórnia, há outro programa de subsídio no nível estadual concedendo, de uma única vez, aos compradores dos carros totalmente elétricos mais 2.500 dólares e para o híbrido plug-in 1.500 dólares.

- Japão: um programa do governo permitiu, desde 2009, um bônus único tanto para carros elétricos como outros carros com combustíveis mais eficientes. O programa foi estendido até 2013 com ajuste, fornecendo um bônus com base na diferença de preço entre o carro elétrico e o a gasolina, sendo limitado a 850.000 ienes (cerca de 6.300 euros).

- China: desde 2010 existe um programa nacional que prevê um bônus único para carros elétricos e carros com célula de combustível. O programa foi estendido até 2015 com algumas revisões. O bônus é entre 35.000 e 60.000 yuanes (cerca de 4.200 e 7.200 euros) para carros totalmente elétricos, dependendo da autonomia da bateria do veículo e 35.000 yuanes (cerca de 4.200 euros) para carros híbridos plug-in com intervalo de bateria não menos de 50 km. Logo, o Renault Zoe receberia um bônus de cerca de 6.000 euros, enquanto o Volvo V60 receberia um bônus de cerca de 4.200 euros.

\section{Incentivos fiscais}

São elementos importantes para estimular a compra dos veículos, existindo quatro principais categorias:

- VAT (value-added tax): no Japão o imposto é de $5 \%$ enquanto na Dinamarca, Noruega e Suécia é de $25 \%$ aplicando-se, geralmente ao preço base do veículo, excluindo qualquer imposto sobre compra e registro. Quanto aos carros totalmente elétricos a Noruega é o único país que exclui carros totalmente elétricos do pagamento de VAT, o que representa uma redução do preço, para o Renault Zoe, por exemplo, de 4.500 euros. Entretanto, na Noruega assim como em outros países, a isenção do VAT para os carros híbridos plug-in não se aplica. Em alguns países a incidência do VAT para os carros elétricos é maior do que para os carros convencionais, isto porque o seu preço base é maior e sujeito a um VAT maior, mesmo após o pagamento de bônus, como ocorre na China e no Japão. Na Alemanha, o Renault Clio, que é um carro convencional com preço base de 13.277 euros está sujeito a 2.523 euros, enquanto o Renault Zoe, com preço base de 21.422 euros é taxado 
em 4.070 euros de VAT. Na Alemanha a alíquota de VAT é de 19\% para carros enquanto que outros produtos como alimentos, livros e flores a alíquota é de $7 \%$.

- $\quad$ one-time purchase/registration tax (imposto único de compra/de registro): alguns países cobram um imposto sobre a compra ou registro do veículo, além do VAT, e proporcionam uma redução de impostos para os carros totalmente elétricos. Na Holanda o imposto depende do nível de emissão de $\mathrm{CO}_{2}$ do veículo, com taxas mais elevadas para diesel do que para os veículos a gasolina. Veículos a gasolina com menos de $95 \mathrm{~g} / \mathrm{km}$ (gasolina) ou a diesel com menos de $88 \mathrm{~g} / \mathrm{km}$ estão isentos do imposto de registro. No caso do Renault Zoe, o valor do benefício equivale apenas a 500 euros, uma vez que as emissões do Renaut Clio $(99 \mathrm{~g} / \mathrm{km})$ ficam apenas ligeiramente acima do limite de $95 \mathrm{~g} / \mathrm{km}$. No caso do Volvo V60, o benefício resultante é bem superior, cerca de 11 mil euros, pois a versão V60 não-híbrido emite 169 g/ $\mathrm{km}$ de $\mathrm{CO}_{2}$ e é um veículo diesel, de modo que as taxas de imposto aplicadas são bastante elevadas. Outros mercados com um forte efeito de imposto de registro são a Dinamarca e Noruega. Na Dinamarca, o cálculo é com base no preço do veículo, equipamentos de segurança a bordo e o consumo de combustível, e os carros totalmente elétricos estão isentos do imposto de registro. Para o Renault Zoe, a economia estimada é de cerca de 14 mil euros. No caso do híbrido plug-in Volvo V60, o valor base para o cálculo do imposto é de cerca de 77 mil euros, em comparação com cerca de 94 mil euros para a versão diesel regular. Na Noruega, o imposto é baseado no peso do veículo, potência do motor e emissões de $\mathrm{CO}_{2}$ e os carros totalmente elétricos são isentos da taxa de registro. A economia para o Renault Zoe é estimada em torno de 4.100 euros. Para o Volvo V60, um imposto de registro de cerca de 37 mil euros aplica-se à versão PHEV, em comparação com cerca de 35 mil euros para a versão diesel regular.

- annual circulation tax: alguns países cobram um imposto anual de propriedade do veículo, mas proporcionam uma redução de impostos para carros elétricos. Na Alemanha o imposto é calculado com base nas emissões de $\mathrm{CO}_{2}$ e na capacidade do motor do veículo. Carros totalmente elétricos e híbridos plug-in estão isentos por um período de dez anos a partir da data do primeiro registro. Para o Renault Zoe, cujo preço base na Alemanha é de 21.422 euros, a isenção representa uma economia de 20 euros por ano, enquanto que o plug-in Volvo V60, cujo preço base é de 51.571 euros, a economia é cerca de 170 euros. Na Holanda o efeito é maior, pois o imposto geralmente é baseado no peso do veículo. Até o final de 2013 todos os carros que emitiam menos de $111 \mathrm{~g} / \mathrm{km}$ (gasolina) ou $96 \mathrm{~g} / \mathrm{km}$ (diesel) de $\mathrm{CO}_{2}$ estavam isentos do imposto. A economia anual no caso do Renault Zoe é estimada em torno de 380 euros, 
no caso do Volvo V60 cerca de 1.900 euros. Os limites para isenção fiscal foram ajustados a partir de janeiro 2014 por um período de quatro anos, de forma que apenas os carros com emissão de menos de $50 \mathrm{~g} / \mathrm{km}$ de $\mathrm{CO}_{2}$ ainda estão isentos do imposto de circulação anual.

- company car tax: carros de empresa são muito populares em muitos países europeus. Na Alemanha, em 2012, apenas 38\% dos automóveis novos de passageiros foram registrados por proprietários privados, enquanto $62 \%$ foram registrados como carros da empresa, sendo um percentual significativo. O mesmo ocorre para os carros elétricos já que em 2012399 carros totalmente elétricos foram registrados por proprietários privados, em comparação com 2.617 registrados como carros de empresas. A ideia básica do sistema de carros de empresas é que ao invés de pagar um salário mais elevado ao seu empregado, a empresa oferece para fornecer-lhe um carro, arcando com todos os encargos relacionados, geralmente incluindo os custos de combustível. O empregado, por outro lado, tem acesso a um que pode ser usado para viagens particulares, porém, em troca, tem que pagar um imposto especial, o company car tax , para usufruir do benefício de ter acesso gratuito a um veículo. Na Holanda, normalmente, $25 \%$ do preço do veículo é considerado como parte da renda do motorista e está sujeito ao imposto de renda. Em 2013, os automóveis de passageiros cujo nível de $\mathrm{CO}_{2}$ não ultrapassasse a $50 \mathrm{~g} / \mathrm{km}$ foram excluídos do imposto de automóveis corporativos. Carros emissores de 51-95 g/km (gasolina) ou 51-88 g/km (diesel) estavam apenas sujeitos a um benefício de $14 \%$ da renda tributável. Os benefícios estimados no caso do Renault Zoe são cerca de 1.100 euros por ano, e no caso do Volvo V60, cerca de 4.300 euros por ano, por um período de cinco anos. A partir de 2014, os carros corporativos com $50 \mathrm{~g} / \mathrm{km}$ de $\mathrm{CO}_{2}$ ou menos deixaram de ser totalmente isentos de tributação.

\section{Economia nos custos de combustível}

- $\quad$ Os preços da gasolina e da eletricidade variam em todos os países. A Noruega tem preços relativamente elevados da gasolina, mas tarifas relativamente baixas de energia elétrica, assim as economias de custos resultantes da mudança para um carro elétrico são maiores do que em outros países. Já na Alemanha, o preço da gasolina é menor, em relação aos demais países europeus, enquanto o preço da eletricidade doméstica é comparativamente maior, logo a economia estimada é menor. Na China, o preço da eletricidade é significativamente mais baixo do que o da gasolina, e, portanto as economias percentuais de mudança para um veículo elétrico são altas. No entanto, porque os preços da gasolina são baixos, comparados com outros mercados, as economias absolutas estão em seu limite mais baixo. A economia de custos de combustível é considerada como um incentivo para o carro elétrico. 
Ocorre que alguns países, por conta do preço maior da energia elétrica em relação à gasolina, poderiam aumentar as tarifas sobre a eletricidade utilizada para veículos do que para a eletricidade doméstica, a fim de explicar a maior eficiência dos carros elétricos em comparação com os carros de motores a combustão e a eliminação de impostos que estão associadas a estes motores poluentes. Entretanto, não existe um movimento para maior taxação de energia elétrica como combustível de carros elétricos, sendo considerada então uma forma dos governos incentivarem a compra e uso desses carros ${ }^{5}$.

As vendas de carros elétricos têm aumentado não só nos Estados Unidos como também na Europa, especialmente França, Alemanha e Noruega. A Noruega é um país com consideráveis reservas de hidrocarbonetos, maior produtora de petróleo na Europa e exportador significativo de gás natural, que poderia torná-la uma candidata improvável para inserir o carro elétrico na mobilidade urbana. Em novembro de 2013 quase 1.700 carros $100 \%$ elétricos foram vendidos, incluindo os importados usados (Gráfico 1). Considerando que a população da Noruega é de 5 milhões de habitantes, a linha mostra um número progressivo da venda de carros elétricos nos últimos meses de 2013, fazendo com que a taxa atual da adoção de carros elétricos da Noruega seja a mais alta do mundo. O Tesla Model S foi o carro elétrico mais vendido em setembro de 2013 e o Nissan Leaf o mais vendido em outubro do mesmo ano, atingindo 5,6\% do mercado de carros novos (ENERGY POLICY INFORMATION CENTER, 2014).

Gráfico 1 - Vendas de carros 100\% elétricos na Noruega em 2013

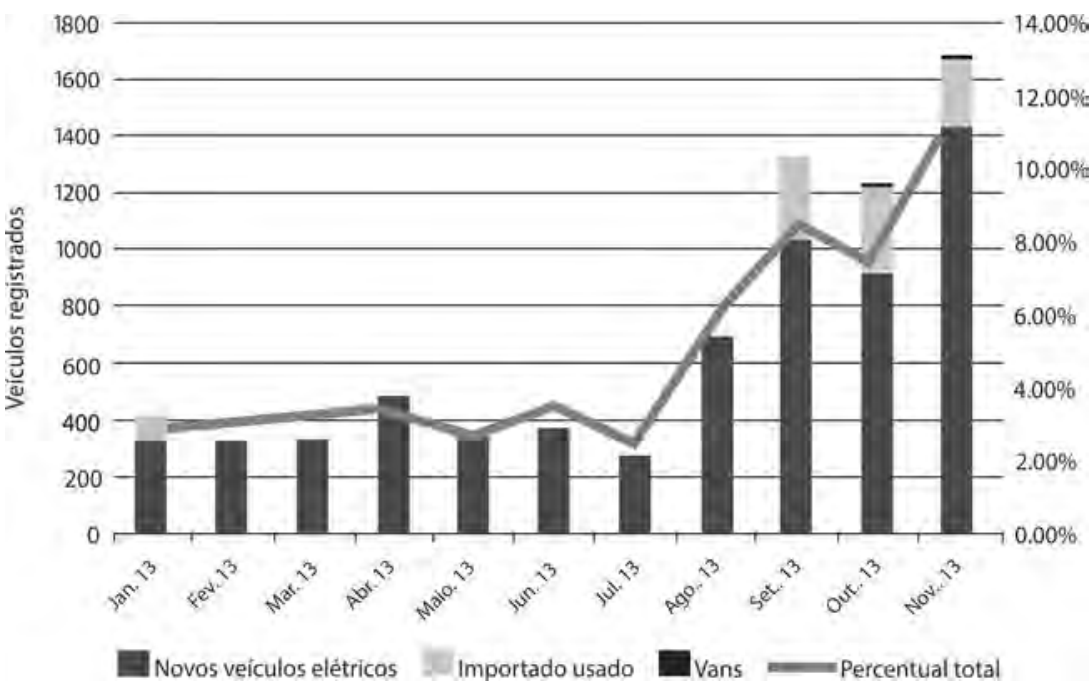

Fonte: ENERGY POLICY INFORMATION CENTER, 2014. 
As razões para o sucesso dos carros elétricos na Noruega são compreendidas. A maioria de sua população é centrada perto da capital Oslo, reduzindo a demanda de viagens de longa distância, mais de 4.000 estações de carregamento já foram instaladas no pequeno país, 127 dos quais são carregadores rápidos e os preços da gasolina são elevados, mesmo para os padrões europeus, com média de US\$ 9 por galão, já que a Noruega consome cerca de 13\% da sua produção de petróleo, exportando a grande maioria. Além disso, o país oferece uma série de incentivos que vão desde estacionamento gratuito para carros elétricos, viagens gratuitas em ferry boats, estradas com acesso livre aos pedágios, até redução de impostos sobre a aquisição dos carros elétricos. (ENERGY POLICY INFORMATION CENTER, 2014)

O governo norueguês está subsidiando de forma agressiva os carros elétricos com quase $100 \%$ na compra do veículo. Ao isentar carros elétricos de impostos típicos e taxas adicionais, a Noruega tem realizado grandes esforços para tornar a propriedade do carro elétrico mais atraente. Esses benefícios vêm quase que inteiramente das receitas e não de subsídios diretos, pois a isenção ocorre a partir dos impostos normalmente cobrados sobre a aquisição de carros a gasolina. (ENERGY POLICY INFORMATION CENTER, 2014) Entretanto, com a crescente pressão para que os incentivos tanto fiscais quanto para a venda sejam reduzidos o governo norueguês já sinaliza redução dos incentivos para os próximos anos. O Tesla S, modelo $100 \%$ elétrico é o mais vendido enquanto que veículos movidos a baterias já representam 25\% dos emplacamentos de carros zero-quilômetro, representando um recorde mundial. (O GLOBO, 2015)

A política de incentivos na Noruega foi tão satisfatória que, em Oslo, os congestionamentos têm sido provocados pelo aumento de carros elétricos na cidade. Considerando que esses carros usam a faixa seletiva de ônibus (Figura 2), os motoristas desses veículos têm argumentado que os atrasos causados pelos carros elétricos trazem um custo pois, segundo eles, o tempo perdido no trânsito por milhares de passageiros de ônibus é muito maior que o tempo ganho por algumas dezenas de condutores de carros elétricos. (FOLHA DE SÃO PAULO, 2014)

Por meio de políticas públicas, o governo norueguês, ao longo das últimas décadas, tem buscado o bem-estar a sua população, considerando que o termo "desenvolvimento sustentável" foi cunhado pela ex-primeira ministra da Noruega Gro Harlem Brundtland quando, na década de 1980, a Organização das Nações Unidas (ONU) Ihe encomendou um estudo que originou o "Relatório Brundtland" ou "Nosso Futuro Comum". De acordo com o relatório, ser sustentável significa conseguir prover as necessidades das gerações presentes sem comprometer a capacidade das gerações futuras em garantir as próprias necessidades. (ENVOLVERDE JORNALISMO E SUSTENTABILIDADE, 2015) No contexto do documento, o desenvolvimento sustentável, em sua essência, é um processo de transformação no qual a exploração dos recursos, a direção dos investimentos, a orientação do desenvolvimento tecnológico e a mudança institucional se harmonizam e reforçam o potencial presente e futuro, a fim de atender às necessidades e aspirações humanas (DIAS, 2011). Assim, a adoção 
Figura 2 - Carros elétricos congestionam a faixa de ônibus durante o horário de rush, em Oslo, capital da Noruega

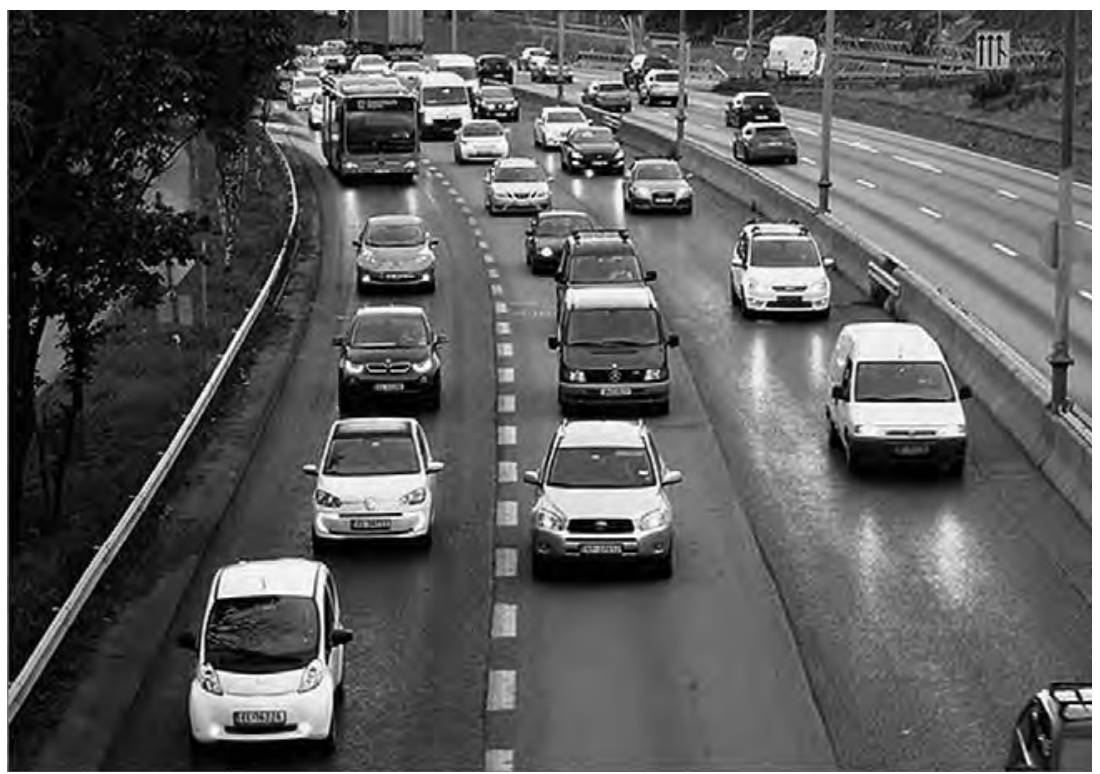

Fonte: FOLHA DE SÃO PAUL0, 2014.

de incentivos generosos do governo norueguês aos carros elétricos compactua com a busca em reduzir a emissão de gases poluentes dos carros convencionais, responsáveis por 10\% das emissões totais no país (FOLHA DE SÃO PAULO, 2014).

A China, em um esforço para promover a inserção de mais veículos não convencionais à frota anunciou, em 2014, que todos os carros 100\% elétricos, híbridos ou movidos a células de combustível estariam isentos de impostos sobre compra até 2017. Com o corte, que reduz em $10 \%$ o preço de veículos nacionais e importados, o governo chinês espera tornar os ecológicos mais atraentes. A medida é parte da estratégia chinesa de combater os altos níveis de poluição atmosférica em suas grandes cidades. Atualmente, existem cerca de 70.000 carros elétricos em uso na China, mas até 2020 o governo espera que esse número aumente para cinco milhões. Nos últimos anos, o país vem expandindo sua rede de carregamento já que empresas de energia locais, como a State Grid, juntamente com empresas privadas, como a fabricante de carros elétricos Tesla, estão atuando na expansão generalizada de pontos de recarga em várias cidades chinesas. (EXAME.COM, 2014)

\section{Ponorama nacional}

O governo brasileiro, em outubro de 2015, isentou o imposto de importação para automóveis que têm como única forma de energia a eletricidade ou o hidrogênio, 
sendo incluídos na lista de exceções à tarifa externa comum do Mercosul, os extarifários ${ }^{6}$. Até então esse imposto era de 35\%. A decisão publicada pela Câmara de Comércio Exterior (CAMEX) beneficia a tecnologia da célula de combustível, cuja conversão do hidrogênio em eletricidade movimenta o motor. Os carros híbridos plug-in ${ }^{7}$, que têm a bateria alimentada tanto por uma fonte externa quanto por um motor gerador situado no interior veículo, tiveram seu imposto reduzido de $35 \%$ para alíquotas de $2 \%, 4 \%$, 5\% e 7\% dependendo da sua eficiência energética. Contudo, com o objetivo de incentivar as primeiras linhas de montagens de híbridos plug-in no país, esses veículos poderão também serem isentos do imposto de importação se as montadoras os trouxerem em partes para montagem final no Brasil. (SOCIEDADE BRASILEIRA DE VAREJO E CONSUMO, 2015)

Os incentivos preparados pelo governo brasileiro, em 2014, para consumo de veículos com propulsão alternativa, não incluíram os carros totalmente elétricos. O governo, naquele momento, apoiou, com a desoneração do imposto de importação, apenas carros híbridos de autogeração, ou seja, àqueles que aproveitam a energia produzida pela desaceleração ou frenagem do veículo para recarregar as baterias, reduzindo o imposto de importação de 35\% para 2\%, incluídos na lista de produtos beneficiados pelo regime de ex-tarifário. (ANTP, 2014)

A isenção do imposto de importação para os carros totalmente elétricos e híbridos plug-in além de beneficiar as montadoras busca, segundo o governo, inserir o país nas novas rotas tecnológicas, com incentivos a veículos de alta eficiência energética, baixo consumo de combustível e reduzida emissão de poluentes (CAMEX, 2015). Logo, a aprovação de leis que garantam a isenção ou diminuição de impostos sobre os carros elétricos no Brasil, além de incentivos para a sua produção, são fundamentais para a sua difusão. Se houvesse um plano de redução ou isenção de impostos para a produção, tanto no produto final quanto em sua cadeia produtiva, seria possível disponibilizar carros elétricos nacionais com valores aproximados aos dos carros populares a gasolina comercializados hoje no país.

Projetos de carros elétricos nacionais, de empresas emergentes de base tecnológica, estão em andamento, como a VEZ (Veículo de Emissão Zero) do Brasil, que ainda está em fase de investimento sem ter iniciado a fabricação, e a ATTO Nacional Montadora Elétrica. A ATTO está desenvolvendo e testando um carro elétrico urbano de dois lugares - o Atto-3 (Figura 3), com futura produção em Cascavel, no Paraná. Entretanto o que ocorre no Brasil, em relação ao carro elétrico, é o mesmo que vem ocorrendo há tempos em outros setores da indústria nacional. Diferentemente de países desenvolvidos que incentivam fortemente suas indústrias e inovações, o país começa a receber carros elétricos de empresas estrangeiras sem incentivar àqueles que, legitimamente, se desenvolvem e serão produzidos no país.

Uma preocupação dos empreendedores brasileiros é a isenção de impostos sobre importações de carros elétricos, pois prejudicaria atividades de P\&D e as iniciativas da indústria nacional. A venda de carros elétricos no Brasil, sejam eles 
Figura 3 - Atto 3 protótipo de testes

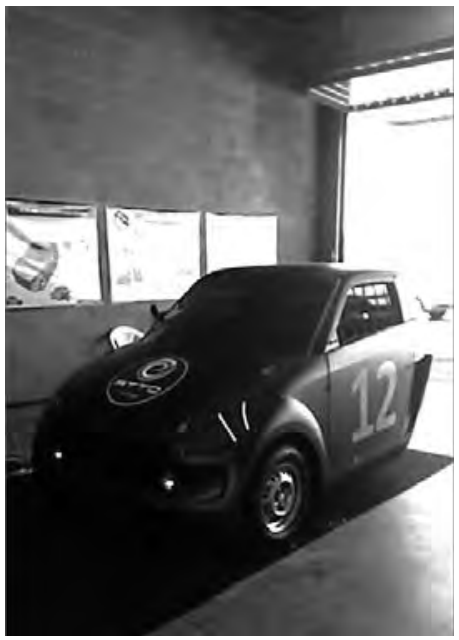

Fonte: Arquivo pessoal da ATTO Nacional Montadora Elétrica. nacionais ou estrangeiros, é essencial para o processo de difusão, mas é importante que a indústria nascente conte com incentivos governamentais para enfrentar a concorrência. Assim, uma iniciativa que isente impostos sobre os carros elétricos desenvolvidos e produzidos no Brasil, isentando também de impostos sua cadeia de suprimento, além de proteger e incentivar as iniciativas da indústria nacional pode contribuir para que projetos consigam sair do papel criando um mercado nacional e competitivo. (VEZ VEÍCULO DE EMISSÃO ZERO, 2015)

Os carros elétricos têm menos custos de manutenção já que não precisam de mudanças de óleo e outras operações de manutenção, pois os motores têm menos peças móveis. $\mathrm{Na}$ realidade todos os carros totalmente elétricos têm uma fração das partes móveis de carros a gasolina e são muito confiáveis. Além de não haver mudanças de óleo, não há velas de ignição, conversores catalíticos ou outro equipamento de emissão. Como resultado, os carros só precisam ser limpos uma vez ou duas vezes por ano para verificar os sistemas do veículo e girar os pneus.

Os custos de manutenção constituem estímulos para a difusão de carros elétricos. No Brasil, a manutenção dos carros elétricos que existem no país, basicamente de frotistas, tem sido realizada pelos fabricantes. Entretanto, o fato das oficinas no Brasil não estarem preparadas hoje para esta nova tecnologia não significa que não estarão caso haja mercado. Na realidade isso não significa um obstáculo para a difusão, pois haverá capacitação apenas para a parte eletrônica, já que o controle da mecânica será igual. Além disso, não exigirão mudanças de infraestrutura nas oficinas para atender aos carros elétricos. Logo, tem-se um ativo complementar, no caso as oficinas de manutenção, que deverá se adaptar para a eletricidade, em termos de manutenção de carros, a partir do que já existe.

Os custos com combustível constitui hoje o principal estímulo a difusão do carro elétrico, pois o custo por km rodado é menor que o carro a gasolina, mesmo considerando a variação dos preços relativos de gasolina e energia elétrica; ou seja, o custo da energia elétrica despendida pelos carros elétricos, com um sistema de armazenamento de energia em baterias, é bastante inferior ao custo do combustível utilizado por carros com motores a combustão interna, para a mesma distância percorrida e em condições idênticas de utilização. Assim, da mesma forma que o custo de manutenção, o custo com o "combustível" do carro elétrico representa um ponto positivo para a aquisição e difusão do carro elétrico. 
Apesar desses pontos positivos, o carro elétrico ainda é caro devido ao custo da bateria. No Brasil o preço ainda é maior devido ao imposto de importação pois os carros são importados e tem uma alíquota elevada. Assim, é necessário realizar, no âmbito fiscal, avanços para trazer os preços para um patamar próximo dos carros convencionais, já que existe um diferencial significativo de preço que necessita ser reduzido para viabilizar a comercialização do carro elétrico em escala industrial.

\section{Conclusão}

A implantação da infraestrutura de abastecimento tem sido muito lenta. É claro que praticamente todas as montadoras têm buscado desenvolver carros elétricos, a bateria ou híbridos. A eficiência destes carros já é comprovada. O que tem que se buscar é viabilizá-los, em termos de custo inicial e de facilidade de recarga. Torná-los atraentes ao consumidor é o grande desafio. Incentivos para a aquisição dos carros elétricos são importantíssimos, mas favorecer a construção de infraestrutura de abastecimento é primordial.

Percebe-se, atualmente, que a competitividade não se apoia tanto no desempenho de setores e empresas isolados, mas sim no funcionamento eficiente de cadeias de valor nas quais interagem diferentes agentes, cujas atividades cooperam para o desenvolvimento da cadeia como um todo. A interação e complementaridade entre esses diferentes agentes podem gerar lucros que os atores não obteriam se atuassem isoladamente no mercado. A questão hoje não é mais o carro elétrico em si. Ele já existe e seu avanço tecnológico tem sido significativo. O que é necessário hoje é desenvolver e alavancar uma infraestrutura de recarga que dê suporte ao seu definitivo estabelecimento.

Desta forma, é fundamental a parceria do Estado com os agentes privados, no caso a parceria com as empresas privadas que estão investindo tanto na produção dos carros elétricos quanto na criação de ativos complementares, para promover o seu desenvolvimento. $\mathrm{O}$ fato é que apenas incentivos fiscais podem não ser suficientes para alavancar as vendas dos veículos em questão. Embora países europeus e Estados Unidos disponibilizem incentivos fiscais para este tipo de carro, eles ainda não são atraentes aos consumidores. O consumo desses carros é afetado pela ausência de infraestrutura pois o indivíduo não irá adquirir um carro que não sabe onde abastecer. Logo, os incentivos são relevantes, mas a implementação de uma infraestrutura também é primordial, e o Estado em cooperação com os agentes privados devem criar condições reais não somente para o desenvolvimento tecnológico do carro movido a energia elétrica, mas também a sua difusão.

A popularização da mobilidade elétrica fará com que o carro elétrico se torne cada vez mais acessível ao consumidor final. Por enquanto os carros totalmente elétricos, especialmente da Aliança Renault-Nissan, estão sendo vendidos para empresas em frotas institucionais. Assim, desenvolver infraestrutura de recarga das baterias, como 
também estimular financeiramente a aquisição desses veículos, são condições chaves para viabilizar e difundir o carro elétrico e o apoio governamental é fundamental para dar o impulso inicial aos carros elétricos.

A difusão da tecnologia do motor elétrico pode, no longo prazo, alterar a estrutura industrial criando ou mesmo destruindo empresas e setores, influenciando o ritmo de crescimento econômico e a competitividade de empresas e países. O desenvolvimento dos ativos complementares deverá seguir então a mesma trajetória dos carros elétricos e seu desenvolvimento dependerá, em muito, do padrão em que o carro elétrico se estabeleça. Os players partidários dos carros elétricos não dispõem ainda de força para enfrentar a enraizada cadeia produtiva do motor a combustão interna. A utilização do etanol na gasolina, tecnologia desenvolvida no Brasil que permite menores emissões de poluentes, principalmente se comparada com modelos movido somente a gasolina, representa mais uma dificuldade à chegada em massa dos carros totalmente elétricos. A existência de políticas de estímulos à bioenergia explica, em parte, a falta de prioridade atribuída pelo governo brasileiro à difusão do carro elétrico.

\footnotetext{
Notas

1 Tese defendida no PPED-IE-UFRJ no dia 30 de março de 2015 com a orientação do Prof. Paulo Bastos Tigre, e tendo como título " Condicionantes da difusão do carro elétrico no Brasil: análise dos fatores institucionais, econômicos e técnicos".

${ }^{2}$ A cobrança horo-tarifária regulamentada pela ANEEL (Agência Nacional de Energia Elétrica) permite dar desconto em horários de menor demanda e sobretaxar no pico (medidor bidirecional inteligente). A cobrança em roaming com medidor inteligente permite identificar o usuário pelo veículo e não pela "tomada" para fazer a cobrança. O carro elétrico passa a ser considerado um "consumidor móvel", pois tem a mobilidade para ora carregar a energia em um determina local e ora carregar em outro. Ocorre que, nessas movimentações o veículo pode utilizar a energia de diferentes concessões, por exemplo: um cliente residente em Campinas, onde a distribuidora de energia é a CPFL Energia, pode ter que viajar com seu carro elétrico até a capital São Paulo, onde a distribuidora é a AES Eletropaulo, em que não é cliente. Nesse caso, como será a cobrança da energia consumida no carregamento em SP? No Brasil, existem 67 distribuidoras de energia elétrica. Logo, essa é uma das questões em que o projeto da CPFL Energia pretende aprofundar.

${ }^{3}$ Frotistas são pessoas jurídicas que utilizam os veículos em seus processos de logística, vendas, marketing etc.

${ }^{4}$ VAT (value-added tax) ou taxa de valor adicional. Este imposto começou a ser cobrado em 1973 na Grã-Bretanha e hoje aplicado em muitos países. No Brasil tem-se o ICMS (Imposto sobre Circulação de Mercadorias e Serviços), IPI (Imposto sobre Produtos Industrializados) e o ISS (Imposto Sobre Serviços), que são similares ao VAT. Entretanto o VAT implica o pagamento de um único imposto.

${ }^{5}$ A convergência tecnológica entre as redes elétricas inteligentes, os pequenos geradores individuais eólicos e solares e os carros elétricos, compartilhando-se equipamentos eletrônicos de controle, baterias, softwares e interfaces, reduz drasticamente o custo de aquisição ou adequação e permite ganhos para a utilização da energia elétrica na residência permitindo benefícios para usuários e operadores, como também reduz o custo da mobilidade pela eficiência. Logo, torna-se solução para vários problemas e gerando também oportunidades.

${ }^{6}$ O regime de ex-tarifário consiste na redução temporária da alíquota do imposto de importação de bens de capital (BK) e de informática e telecomunicação (BIT), assim grafados na Tarifa Externa Comum do Mercosul (TEC), quando não houver a produção nacional equivalente. Representa uma redução no custo do investimento. (MINISTÉRIO DO DESENVOLVIMENTO, INDÚSTRIA E COMÉRCIO EXTERIOR, 2015).

${ }^{7}$ Os carros híbridos plug-in combinam um motor convencional a combustão interna com outro elétrico, sendo uma combinação dos carros puramente elétrico e dos carros híbridos. Os carros híbridos não se conectam a uma fonte externa e a energia elétrica que move o motor elétrico é produzida no interior do próprio veículo por um motor de combustão interna que aciona o gerador, podendo ser gasolina, o etanol ou óleo diesel. A energia não utilizada é armazenada para ser usada quando necessária.
} 


\section{Referências bibliográficas}

ABB GROUP - AUTOMATION AND POWER TECHNOLOGIES. Fastened selecciona a ABB para construir a maior rede holandesa de carregamento rápido de veículos eléctricos. Disponível em: <http://www.abb.com/cawp/seitp202/e68bb83ec1bc8fbbc1257bb40059727e.aspx>. Acesso em: 15 de agosto de 2015.

ADENE. AGÊNCIA PARA ENERGIA. Mobi.E Disponível em: <http://www2.adene.pt/pt-pt/ NavegacaoDeTopo/EnergiaNosTransportes/MobilidadeElectrica/Paginas/Mobi-E.aspx>. Acesso em: 31 de agosto de 2015.

ANTP AGÊNCIA NACIONAL DE TRANSPORTES PÚBLICOS. Carro híbrido terá incentivo e elétrico, não. 05 de setembro de 2014. Disponível em: <http://antp.org.br/website/noticias/ clipping/show.asp?npgCode=9EE56194-FB2D-4EB5-9030-E3D156D6265D >. Acesso em: 08 de novembro de 2015.

AUTOMOTIVE BUSINESS (a). Fastned e ABB implementarão rede de recarga rápida na Holanda. Disponível em: <http://www.automotivebusiness.com.br/noticia/17438/fastned-e-abbimplementarao-rede-de-recarga-rapida-na-holanda>. Acesso em 26 de outubro de 2015.

AUTOMOTIVE BUSINESS (b). Renault instala painéis solares em fábrica do Brasil. Disponível em: $<$ http://www.automotivebusiness.com.br/noticia/20550/renault-instala-paineis-solares-emfabrica-do-brasil>. Acesso em 09 de outubro de 2015.

CAMEX CÂMERA DE COMÉRCIO EXTERIOR. Camex aprova redução da alíquota do Imposto de Importação para carros elétricos e movidos à células de combustível. 27 de outubro de 2015. Disponível em: <http://www.camex.gov.br/noticias/ler/item/659> Acesso em: 07 de novembro de 2015.

COWAN, R.; HULTÉN, S. Escape lock-in: the case of the electric vehicle. Technological Forecasting and Social Change, vol. 53, n. 1996, p. 61-80. Disponível em: <http://www.cgl.uwaterloo. ca/ racowan/escape.pdf>. Acesso em: 14 de novembro de 2013.

CROWN CROATION WORLD NETWORK. Marin Soljacic Croatian physicist and inventor founder of WiTricity Corp. announces "GOODBY WIRES.... Disponível em: <http://www.croatia.org/crown/ articles/10510/1/Marin-Soljacic-Croatian-physicist-and-inventor-founder-of-WiTricity-Corpannounces-quotGOODBY-WIRESquot.html> Acesso em: 10 de julho de 2014.

DIAS, R. Gestão ambiental: responsabilidade social e sustentabilidade. São Paulo: Atlas, 2011. ENERGY POLICY INFORMATION CENTER. Lessons from Norway: EVs and Oil Production Highly Compatible. Disponível em: <http://energypolicyinfo.com/2013/12/lessons-from-norwayelectric-vehicles-and-oil-production-highly-compatible/>. Acesso em: 15 de julho de 2014.

ENVOLVERDE JORNALISMO E SUSTENTABILIDADE . A trilha da sustentabilidade. 14 de outubro de 2014. Disponível em: <http://envolverde.com.br/sociedade/trilha-da-sustentabilidade/> Acesso em: 11 de fevereiro de 2015.

EXAME.COM . China elimina impostos sobre carros elétricos. 11 de julho de 2014. Disponível em: <http://exame.abril.com.br/economia/noticias/china-elimina-impostos-sobre-carroseletricos>. Acesso em: 20 de outubro de 2015.

FOLHA DE SÃO PAULO. Carros elétricos atrapalham o trânsito em Oslo. 03 de setembro de 2014. Disponível em: <http://www1.folha.uol.com.br/mercado/2014/09/1509922-carroseletricos-atrapalham-o-transito-em-oslo.shtml> Acesso e: 11 de fevereiro de 2015.

FREEMAN, C.; SOETE, L. A economia da inovação industrial. Campinas, SP: Editora da Unicamp, 2008. 
GREEN TRANSPORTATION. INFO. Open Charge Point Protocol \& OCPP Organization. Disponível em: <http://greentransportation.info/ev-charging/protocols/ocpp.html>. Acesso em: $10 \mathrm{de}$ julho de 2014.

HEVO POWER. Disponível em: <http://hevopower.com/>. Acesso em: 10 de julho de 2014. INSTITUTION OF MECHANICAL ENGINEERS. Electric Vehicle infrastructure. Transport Policy System, feb. 2010.

MINISTÉRIO DO DESENVOLVIMENTO, INDÚSTRIA E COMÉRCIO EXTERIOR. O que é o Ex-tarifário? Disponível em: <http://www.mdic.gov.br/sitio/interna/interna. php?area=2\&menu=1174> Acesso em: 08 de novembro de 2015.

MOCK, P.; YANG, Z. Driving electrification. A global comparison of fiscal incentive policy for electric vehicles. White Paper. ICCT The International Council on Clean Transportation. May 2014. Disponível em: $<$ http://www.theicct.org/sites/default/files/publications/ICCT_EV-fiscalincentives_20140506.pdf >. Acesso em: 27 de outubro de 2014.

MOWERY, David C.; ROSENBERG, N. Trajetórias da inovação: a mudança tecnológica nos Estados Unidos da América do Norte no século XX. Campinas, SP: Editora Unicamp, 2005.

O GLOBO. Noruega reduzirá incentivos aos carros elétricos. Disponível em: <http://oglobo. globo.com/economia/carros/noruega-reduzira-incentivos-aos-carros-eletricos-16103628> . Acesso em 18 de agosto de 2015.

SOCIEDADE BRASILEIRA DE VAREJO E CONSUMO. Carro elétrico tem tarifa de importação zerada. Disponível em: <http://www.sbvc.com.br/2014/2007543-carro-eletrico-tem-tarifa-deimportacao-zerada/> Acesso em: 08 de novembro de 2015.

TEECE, D. J. Profiting from technological innovation. Research Policy, 15(6), 1986, p. 285-305.

TESLA. Supercharger The Fasted Charging Station on the Planet. Disponível em: <http://www. teslamotors.com/supercharger>. Acesso em: 21 de novembro de 2014.

THE VERGE. Palo Alto will require all new homes to support electric vehicle chargers. Disponível em: <http://www.theverge.com/2013/10/1/4790608/palo-alto-mandates-all-new-homeswired-for-electric-vehicle-chargers >. Acesso em: 12 de dezembro de 2013.

TRANSPORT EVOLVED. Rapid Chargers to Make Israel a Better Place for Electric Cars. Disponível em: <http://transportevolved.com/2014/02/24/rapid-chargers-to-make-israel-a-better-placefor-electric-cars/>. Acesso em: 10 de julho de 2014.

VEZ VEÍCULOS DE EMISSÃO ZERO. Campanha pela isenção de impostos sobre carros elétricos. Disponível em: <http://www.vezdobrasil.com.br/campanha-pela-isencao-de-impostos-sobrecarros-eletricos/>. Acesso em: 23 de agosto de 2015.

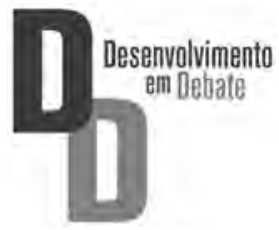

